\title{
Artificial Neural Network for Estimation of Local Scour Depth Around Bridge Piers
}

\author{
Ahmed Shakir Ali Ali ${ }^{1}$, Mustafa Günal ${ }^{2}$ \\ ${ }^{1}$ University of Gaziantep, Faculty of Engineering, Department of Civil Engineering, Gaziantep, Turkey \\ (Corresponding author e-mail: ahmedsh.ali94@gmail.com.); ${ }^{2}$ University of Gaziantep, Faculty of \\ Engineering, Department of Civil Engineering, Gaziantep, Turkey, e-mail: gunal@gantep.edu.tr
}

(Received January 11, 2021; revised August 22, 2021)

\begin{abstract}
Local scour around bridge piers impairs the stability of bridges' structures. Therefore, a delicate estimation of the local scour depth is vital in designing the bridge piers foundations. In this research, MATLAB software was used to train artificial neural network (ANN) models with four hundred laboratory datasets from different laboratory studies, including five parameters: pier diameter, flow depth flow velocity, critical sediment velocity, sediment particle size, and equilibrium local scour depth. The outcomes present that the ANN model with the Levenberg-Marquardt algorithm and 11 nodes in the single hidden layer gives an accurate estimation better than other ANN models trained with different training algorithms based on the regression results and mean squared error values. Besides, the ANN model accurately provides predicted local scour depth and is better than linear and nonlinear regression models. Furthermore, sensitivity analysis shows that removing pier diameter from training parameters diminishes the reliability of prediction.
\end{abstract}

Key words: artificial neural network, bridge pier, hydraulics, local scour

\section{Introduction}

Local scour is a natural phenomenon generated by the denudation of silty ducts' bottom and edges due to the water's flow (Khwairakpam and Mazumdar 2009). Besides, scour takes place in the coastal regions as a result of the waves. The procedure of scouring mechanizations is well established. However, it is not manageable to quantify the quantity of scour at the bridge pier because of the complexity of the cyclic nature of the event and the fact that geometry of the bridge, morphology, the channel of the river, and the hydrologic process is different at each bridge. Scour at bridge

(C) 2021 Institute of Hydro-Engineering of the Polish Academy of Sciences. This is an open access article licensed under the Creative Commons Attribution-NonCommercial-NoDerivs License (http://creativecommons.org/licenses/by-nc-nd/4.0/). 
piers is generally the outcome of the combined influences of three separate scour procedures (local, contraction, and general scour at abutments and piers) that could occur either at the specific moment or independently. As shown in Figure 1, researchers have ordered total scour into the general scour and localized scour. The localized scour includes constriction scour, which is the decrease in the cross-sectional area of the flow of water due to the presence of piers and abutments; leading to an increase in the flow velocity, as a consequence, increase erosion due to flow, and hence reduce the bed elevation across the area concerned by the constriction.

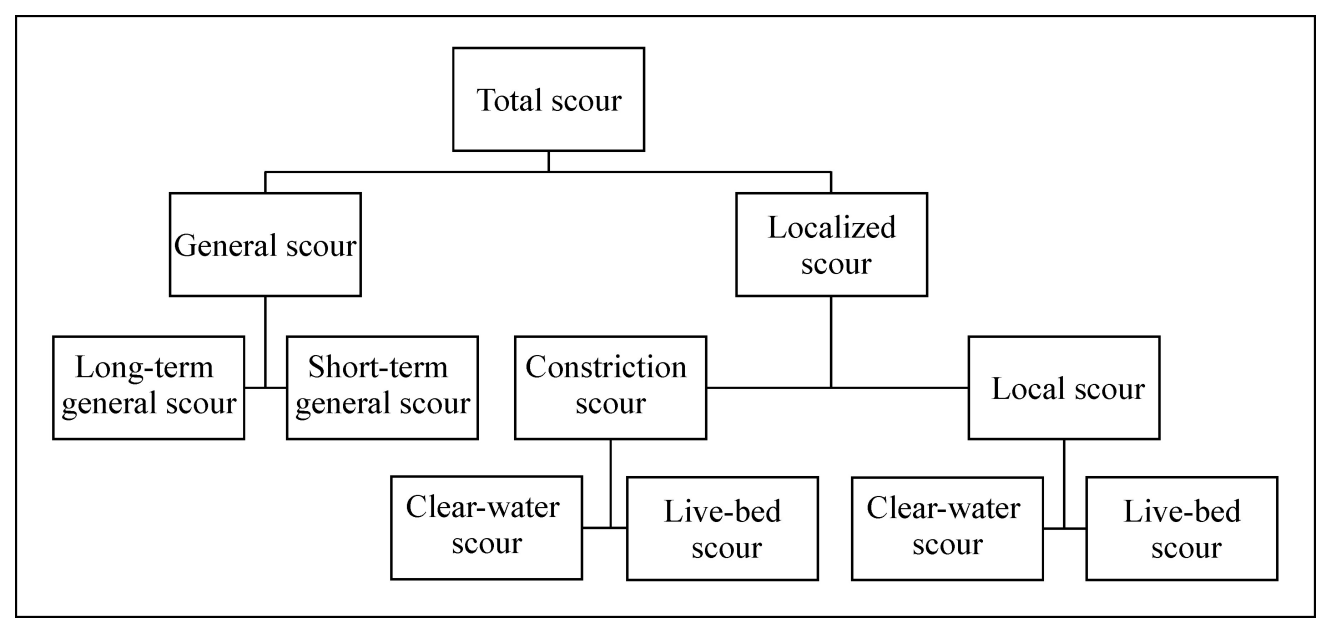

Fig. 1. Scour classification (Cheremisinoff et al 1987)

Another type of localized scour is the local scour, which is directly influenced by a pier or abutment of the bridge that interrupts water flow and combines live bed scour and clear water scour situations. The principal factor distinguishing between the live bed scour and clear water conditions is that the mean velocity $(V \mathrm{~m} / \mathrm{s})$ of the flow upstream of the bridge is less or more significant than the scour-critical velocity $\left(V_{s}\right.$ $\mathrm{m} / \mathrm{s}$ ) needed to relocate the bed material. Therefore, the clear water scour condition happens in $V<V_{S}$. The bed material upstream of the bridge is at ease, referred to as the clearwater condition, because the approach flow does not sustain sediment, while live-bed scour does not occur when the $V>V_{S}$. Additionally, the equilibrium scour depth is accomplished when the material is carried into the scour hole at the same rate at which it is transported out. In the clear water scour condition, the depth of the scour hole extends to grow till equilibrium is reached. Hence, it occurs when the combination of the temporary mean bed shear stress and the turbulent near the bed can no longer eliminate the bed substance from the scour hole at the pier. In live-bed scour, the equilibrium scour depth is reached when the time that sediment enters the scour hole is equivalent to the time that is leaving the hole. Therefore, the depth of scour is an essential parameter for determining the minor depth of foundations as it minimizes 
the lateral capacity of the foundation. For this purpose, inclusive laboratory researches were carried to understand the complex scour process and establish a method of predicting scour depth for various pier locations. However, no generic description has been revealed that can be used in all pier cases to determine the quantity of scour that will happen. Numerous empirical formulae were presented to predict equilibrium scour depth at bridge piers, including Laursen and Toch (1956), Shen (1971), Hancu (1971), Breuser et al (1977), Melville and Sutherland (1988). Besides, improving soft computing techniques supported researchers in utilizing advanced methods to estimate the scour depth around various structures. Jeng et al (2005) employed an artificial neural network to predict equilibrium scour depth and time-dependent scour depth. They developed two Bayesian models with single hidden layers and multiple hidden layers, and they trained ANN models with the combination of dimensional and dimensionless parameters. They noted that the Bayesian neural network model provides more precise scour depth predictions than the current methods. The sensitivity analysis revealed that pier diameter has the most significant influence on equilibrium scour depth. Additionally, predictions based on the original (dimensional) scour data were more accurate than those based on dimensionless data. Bateni et al (2007) applied ANN models with multilayer perceptron (MLP/BP), radial basis function (RBF/OLS), and adaptive neuro-fuzzy inference system (ANFIS) in the calculation of equilibrium and time-dependent scour depth around piers. The research comprised the laboratory data to train and verify the networks, and they trained ANN models with dimensional and non-dimensional parameters. They observed that the neural networks and neuro-fuzzy approaches predict scour depth much more precisely than the present methods, especially multilayer perception with one hidden layer and raw data. They also pointed out that the pier diameter has the most influence on equilibrium scour depth. Guven et al (2012) developed gene-expression programming (GEP) and a multilayer perception model with one hidden layer and a backpropagation algorithm to predict the scour depth around a circular pile due to tides. The models are trained with dimensional and non-dimensional parameters. They concluded that the GEP predicted the scour depth around the pile with better precision than MLP, linear regression, and nonlinear regression models. Sarshari and Mullhaupt (2015) used ANN and empirical methods to predict equilibrium scour depth at bridge piers. They applied a multilayer neural network and the popular backpropagation algorithms in MATLAB, and they trained ANN models with dimensional parameters. They noticed that the neural network prediction results are more precise than the outcomes gained from the empirical models. The training algorithm Levenberg-Marquardt BPG (trainlm) presents more desirable outcomes than other algorithms in MATLAB. Khassaf and Abdulwhab (2016) employed ANN with feed-forward backpropagation algorithms in MATLAB to estimate the maximum local scour depth at cylindrical bridge piers. They observed that ANN gives better outcomes than empirical formulas, particularly the ANN model with Levenberg-Marquardt BPG (trainlm), which includes a single hidden layer and two hidden layers. Besides, the pier diameter has the most signif- 
icant impact on predicting local scour depth based on sensitivity outcomes. Amini et al (2020) used an ANN model with a single hidden layer and three neurons to predict the scour depth at the composite piers of the bridges. They found that the proposed ANN model provides better results than the empirical methods, and the pile cap location and the flow depth have the most effects on the scour depth. However, the literature on applying artificial neural networks to estimate the scour depth at the bridge's abutment has not been reported over an extensive range. This study aims to utilize Artificial Neural Networks trained with laboratory data and various backpropagation algorithms in MATLAB for predicting equilibrium local scour depth around bridge piers. Besides, examining the most critical factors that affect the prediction and performance of modeling with dimensional and non-dimensional variables and comparing the outcomes with linear and nonlinear regression models.

\section{Parameters Governing Scour}

The depth of equilibrium local scour around the bridge piers is influenced by flow, sediment properties, and the geometry of the pier (Melville and Coleman 2000), as shown in the following functional relationship:

$$
d_{s e}=f_{n}\left[\begin{array}{c}
\text { flow }(\rho, \mu, V, y, g, \gamma), \text { sediment }\left(d_{50}, \sigma_{g}, \rho_{s}, V_{C}\right), \\
\text { pier geometry }(b, \alpha, \beta)],
\end{array}\right.
$$

where $d_{s e}$ is the equilibrium scour depth, $\mu$ and $\rho$ are dynamic viscosity of water $\left(\mathrm{m}^{2} / \mathrm{s}\right)$ and fluid density $\left(\mathrm{kg} / \mathrm{m}^{3}\right)$, respectively, $y$ and $V$ are flow depth (m) and mean velocity $\left(\mathrm{m} / \mathrm{s}^{2}\right)$, respectively, $g$ is the gravitational acceleration, $\gamma$ is the correction factor for bed form, $\sigma_{g}$ and $d_{50}$ are standard deviation and median of the particle size distribution $(\mathrm{mm})$, respectively, $V_{C}$ is the critical mean velocity for entrainment of bed sediment $(\mathrm{m} / \mathrm{s}), \rho_{s}$ is the sediment particle density $\left(\mathrm{kg} / \mathrm{m}^{3}\right), b$ is the pier width or pier diameter, and $\beta$ and $\alpha$ are correction factors for flow angle of attack and pier shape. However, the number of parameters in (Eq. 1) can be reduced, as $\gamma$ and $\sigma_{g}$ can be ignored and subscript in $d_{50}$ can be removed from Equation 1 in the case of uniform sediment and abandoned influence of bedform. Moreover, when the angle of flow attack is assumed to be zero, $\beta$ and $\alpha$ parameters could be taken away. Furthermore, $\rho_{s}$ and $\rho$ can be removed due to constant values of these parameters, and the meager effectiveness of viscous, (Eq. 1) could be written as follows (Choi et al 2017):

$$
d_{s e}=f_{1}\left(V, y, d, V_{C}, b\right) .
$$

The dimensional analysis of Equation 2 leads to (Eq. 3) (Choi et al 2017), as shown:

$$
\frac{d_{s e}}{b}=f_{2}\left(\frac{V}{V_{c}}, \frac{y}{b}, \frac{d}{b}\right) .
$$




\section{Artificial Neural Network}

An artificial neural network (ANN) is a comprehensive parallel-distributed information-processing framework that has a valid task feature similar to the brain's biological neural network systems in the human being (Haykin 1999), which is provided by McCulloch and Pitts (1943). The strength of the artificial neural network in distinguishing a relationship from a presented method makes it advantageous in resolving complex wide-ranging problems such as modeling, classification, and nonlinear problems. The characterizes of an ANN are known by determining the connection weight, the structure of the neural network, and activation function. The principles and components of ANN modeling and training steps are exceedingly introduced in the published works of Haykin (1999); Dolling and Varas (2002); Azmatullah et al (2005). Commonly, an artificial neural network contains three layers: input layer, hidden layer, and output layer, and each of these layers acting as a separate computational part, as shown in Figure 2.

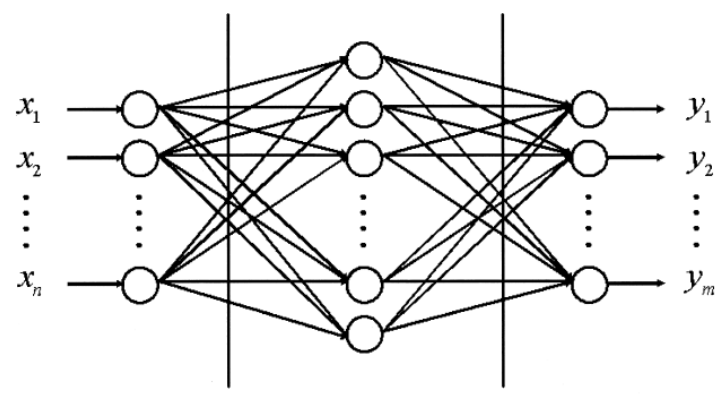

Input Layer $(i) \quad$ Hidden Layer $(j) \quad$ Output Layer $(k)$

Fig. 2. Architecture of an ANN model (Choi and Cheong 2006)

The number of neurons in the hidden layer is a critical parameter determining ANN models' accuracy. Fletcher and Goss (1993) recommended that the suitable number of neurons in the hidden layer range from $(2 n 1 / 2+m)$ to $(2 n+1)$, where $n$ is the number of input neurons and $m$ is the number of output neurons. Commonly, the number of hidden layer neurons is decided by a trial-and-error process. Finally, the model with the most precise results will be applied, which contains the most relevant number of neurons in the hidden layers. In this study, eight ANN feed-forward neural network models with backpropagation algorithms were established to predict the equilibrium local scour depth around bridge piers using a deep learning toolbox in MATLAB. Besides, these ANN models included a single hidden layer with 2-12 nodes to figure out the appropriate number of nodes in the hidden layer. Table 1 shows the backpropagation algorithms used in the training ANN models in MATLAB and the parameters of each ANN model. 
Table 1. ANN models

\begin{tabular}{|c|c|c|c|}
\hline Model name & Function name & Algorithm & Variables \\
\hline DM-1 & TRAINLM & Levenberg-Marquardt backpropagation & $d_{s e}, b, V, y, V_{c}, d$ \\
\hline DM-2 & TRAINRP & Resilient backpropagation & $d_{s e}, b, V, y, V_{c}, d$ \\
\hline DM-3 & TRAINGDA & $\begin{array}{c}\text { Gradient descent with adaptive } l r \\
\text { backpropagation }\end{array}$ & $d_{s e}, b, V, y, V_{c}, d$ \\
\hline DM-4 & TRAINCGF & $\begin{array}{c}\text { Fletcher-Powell conjugate gradient } \\
\text { backpropagation }\end{array}$ & $d_{s e}, b, V, y, V_{c}, d$ \\
\hline DM-5 & TRAINCGP & $\begin{array}{c}\text { Polak-Ribiere conjugate gradient } \\
\text { backpropagation }\end{array}$ & $d_{s e}, b, V, y, V_{c}, d$ \\
\hline DM-6 & TRAINCGB & $\begin{array}{c}\text { Powell-Beale conjugate gradient } \\
\text { backpropagation }\end{array}$ & $d_{s e}, b, V, y, V_{c}, d$ \\
\hline DM-7 & TRAINBFG & BFGS quasi-Newton backpropagation & $d_{s e}, b, V, y, V_{c}, d$ \\
\hline NDM-1 & TRAINLM & Levenberg-Marquardt backpropagation & $\frac{d_{s e}}{b}, \frac{V}{V_{c}}, \frac{y}{b}, \frac{d}{b}$ \\
\hline
\end{tabular}

The log-sigmoid transfer function (LOGSIG) was utilized in the hidden layer that outfits a graded nonlinear response and supports the ANN to transact with any nonlinear cases. The linear transfer function (PURLIN) was utilized as a transfer function between the hidden and output layer (Prasad et al 2012):

$$
\begin{gathered}
\text { LOGSIG }=f(n)=\frac{1}{1+\exp (-n)}, \\
\text { PURLIN }=f(n)=n,
\end{gathered}
$$

where $f(n)$ is the output of the transfer function, and $n$ is the weighted sum of inputs. Moreover, the evaluation of the accuracy of ANN models in the prediction was assessed according to regression value $(R)$ (best value $=1$ ) and mean squared error (MSE) (best value $=0$ ) (Hagan et al 2002, Hagan et al 2009).

$$
\begin{gathered}
R=\frac{\sum_{k=1}^{n}\left(T_{K}-\bar{T}\right)\left(O_{K}-\bar{O}\right)}{(n-1) S_{T} S_{o}}, \\
S_{T}=\sqrt{\frac{1}{n-1} \sum_{k=1}^{n}\left(T_{K}-\bar{T}\right),} \\
S_{T}=\sqrt{\frac{1}{n-1} \sum_{k=1}^{n}\left(O_{K}-\bar{O}\right),} \\
\bar{T}=\frac{1}{n} \sum_{k=1}^{n} T_{K},
\end{gathered}
$$




$$
\begin{gathered}
\bar{O}=\frac{1}{n} \sum_{k=1}^{n} O_{K}, \\
\mathrm{MSE}=\frac{1}{n} \sum_{k=1}^{n}\left(T_{K}-O_{K}\right)^{2},
\end{gathered}
$$

where $n$ is the number of data, $O_{K}$ is the network outcome, $T_{K}$ is the actual target, $\bar{O}$ is the mean value of the network output, $\bar{T}$ is the mean value of the targets.

\section{Dataset}

ANN models were trained with 400 laboratory measurements of the pier scour dataset. These data were taken from the laboratory data available in the PSDb-2014, consisting of 569 measures taken from 17 previous investigations collected by Sheppard et al (2011), Benedict and Caldwell (2014). Throughout a screening method that included data review and statistical study, Sheppard et al (2011) recognized 441 of the laboratory measurements that approximated equilibrium scour depths and applied that data in their research of pier scour. Some of the laboratory measurements compiled by Sheppard et al (2011) are of historical interest. In particular, various of the data collected by Chabert and Engeldinger (1956) and Shen et al (1969) was employed to improve the original Hydraulic Engineering Circular No. 18 (HEC-18) pier-scour equation (Richardson et al 1991). The data consist of variables which are pier width $(b)$, flow velocity $(V)$, flow depth $(y)$, the sediment critical mean velocity $(V c)$, the particle diameter $(d)$, and equilibrium scour depth $(d s e)$. Table 2 shows the sources of data used in the training ANN models.

Table 2. Dataset

\begin{tabular}{|c|c|}
\hline Source of dataset & Number of datasets \\
\hline Chabert and Engeldinger (1956) & 93 \\
\hline Chee (1982) & 37 \\
\hline Chiew (1984) & 101 \\
\hline Coleman (unpublished) & 6 \\
\hline Dey et al (1995) & 18 \\
\hline Ettema (1980) & 97 \\
\hline Ettema et al (2006) & 6 \\
\hline Ettema (1976) & 19 \\
\hline Graf (1995) & 3 \\
\hline Jain and Fischer (1979) & 20 \\
\hline
\end{tabular}

Table 3 presents the range of dimensional variables, while Table 4 shows the range of non-dimensional variables.

Besides, all variables were normalized according to the min-max normalization method to increase prediction efficiency (Dogan et al 2008). 
Table 3. Dimensional dataset

\begin{tabular}{|c|c|}
\hline Dimensional variable & Range \\
\hline$V\left(\mathrm{ft} / \mathrm{s}^{2}\right)$ & $0.54-5.28$ \\
\hline$y(\mathrm{ft})$ & $0.066-3.281$ \\
\hline$d(\mathrm{~mm})$ & $0.24-7.8$ \\
\hline$V_{c}(\mathrm{ft} / \mathrm{s})$ & $0.73-4.81$ \\
\hline$b(\mathrm{ft})$ & $0.095-2.5$ \\
\hline$d_{s e}(\mathrm{ft})$ & $0.049-1.497$ \\
\hline
\end{tabular}

Table 4. Dimensionless dataset

\begin{tabular}{|c|c|}
\hline Dimensionless variable & Range \\
\hline$d_{s e} / b$ & $0-3.084$ \\
\hline$V / V_{C}$ & $0.445-4.690$ \\
\hline$y / b$ & $0.052-20.947$ \\
\hline$d / b$ & $0.304-82.978$ \\
\hline
\end{tabular}

$$
X_{\text {norm }}=\frac{X-X_{\min }}{X_{\max }-X_{\min }},
$$

where $X_{\text {norm }}$ is the normalized value of a variable, $X$ is any value of the dataset, $X_{\max }$ is the maximum value of the whole dataset, and $X_{\min }$ is the minimum value of the whole dataset. The dataset was divided randomly into $70 \%$ for training, $15 \%$ for validation, and $15 \%$ for test.

\section{Results and Discussion}

ANN models with various backpropagation algorithms and 2-12 nodes in the single hidden layers were run in MATLAB using a deep learning toolbox. Each ANN model provided different results, and the performance of ANN models was assessed according to the regression value (R) and mean squared error (MSE) of the training and test data set. The ANN model DM-1 with training algorithm Levenberg-Marquardt backpropagation (TRAINLM) and 11 nodes in the hidden layer showed the best results among ANN models. Moreover, model DM-1 performance is better than ANN model NDM-1, trained with the same training algorithm, the number of nodes in the hidden layer (11 nodes), and dimensional and non-dimensional parameters, as shown in Table 5. Figure 3 - Figure 9 demonstrates the performance of ANN models. Besides, ANN model DM-1 provided better predicted local scour depth results than ANN model NDM-1, linear regression model, and nonlinear regression model, as shown in Figure 10 - Figure 12.

\section{Sensitivity Analysis}

Artificial neural networks could be used to assess the significance of dimensional and non-dimensional input variables in estimating the local scour depth. For this purpose, 
Table 5. Performance of ANN model DM-1 and NDM-1

\begin{tabular}{|c|c|c|c|c|c|c|}
\hline Models & $\begin{array}{c}\mathrm{R} \\
\text { training }\end{array}$ & $\begin{array}{c}\text { MSE } \\
\text { training }\end{array}$ & $\begin{array}{c}\mathrm{R} \\
\text { test }\end{array}$ & $\begin{array}{c}\text { MSE } \\
\text { test }\end{array}$ & Nodes & $\begin{array}{c}\text { Function } \\
\text { name }\end{array}$ \\
\hline DM-1 & 0.9585 & 0.0025 & 0.9290 & 0.0032 & 11 & TRAINLM \\
\hline NDM-1 & 0.7023 & 0.009 & 0.7128 & 0.0088 & 11 & TRAINLM \\
\hline
\end{tabular}
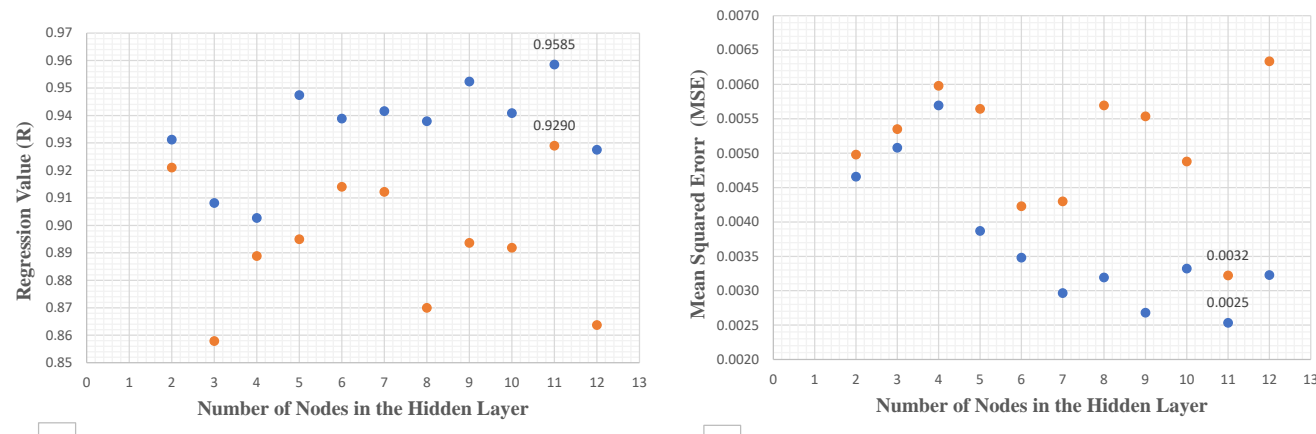

- R training $\bullet$ R test

Fig. 3. Performance of ANN model DM-1: (a) R values; (b) MSE

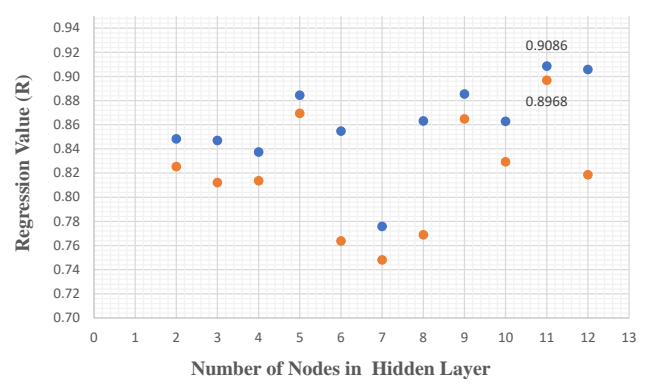

a

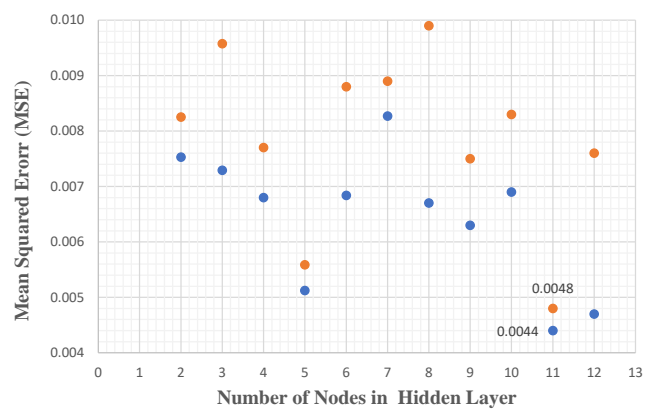

b - MSE Training - MSE Test

Fig. 4. Performance of ANN model DM-2: (a) R values; (b) MSE

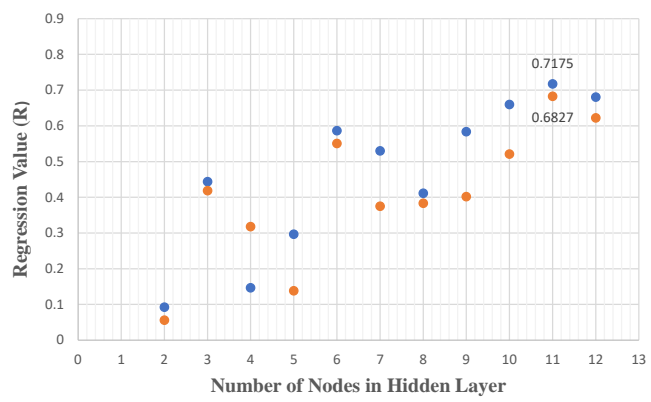

a

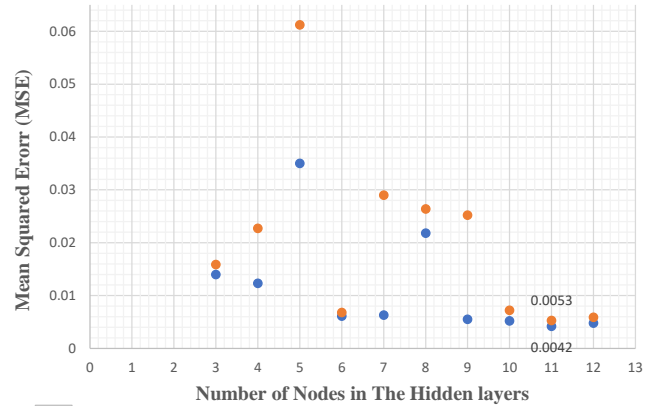

b

Fig. 5. Performance of ANN model DM-3: (a) R values; (b) MSE 


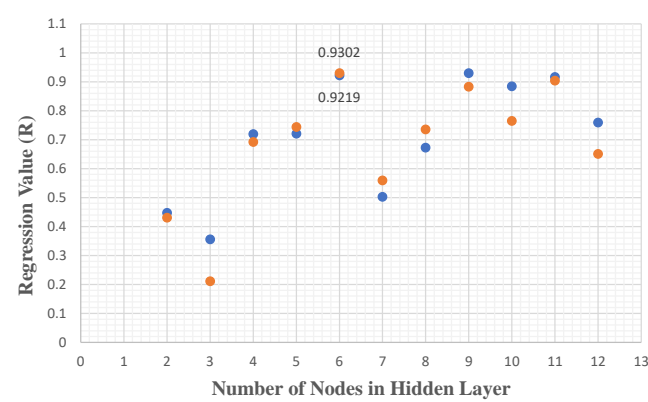

- R training - R test

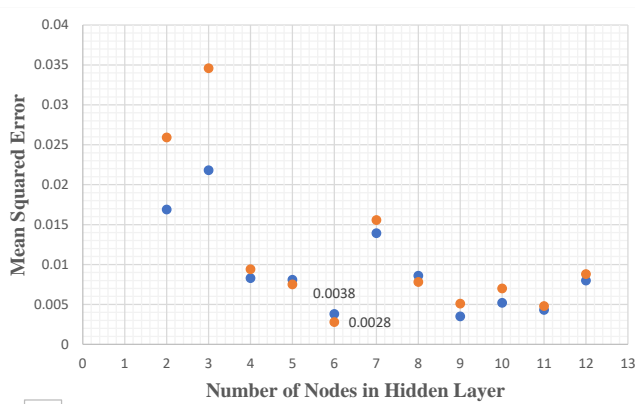

b

- MSE training - MSE test

Fig. 6. Performance of ANN model DM-4: (a) R values; (b) MSE

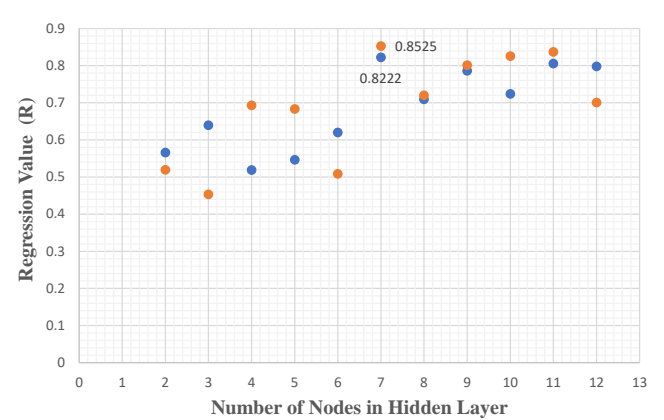

a

- R training $\bullet$ R test

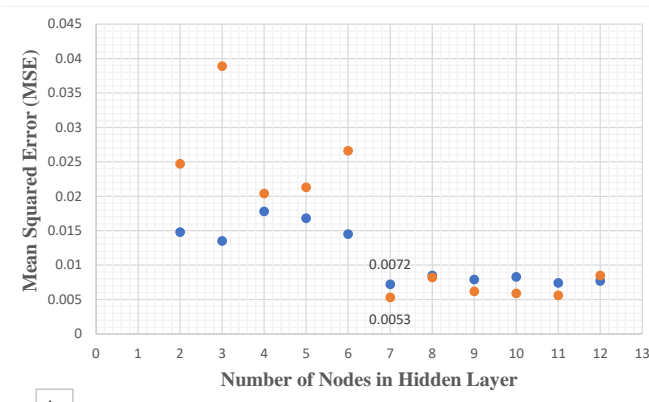

b

Fig. 7. Performance of ANN model DM-5: (a) R values; (b) MSE
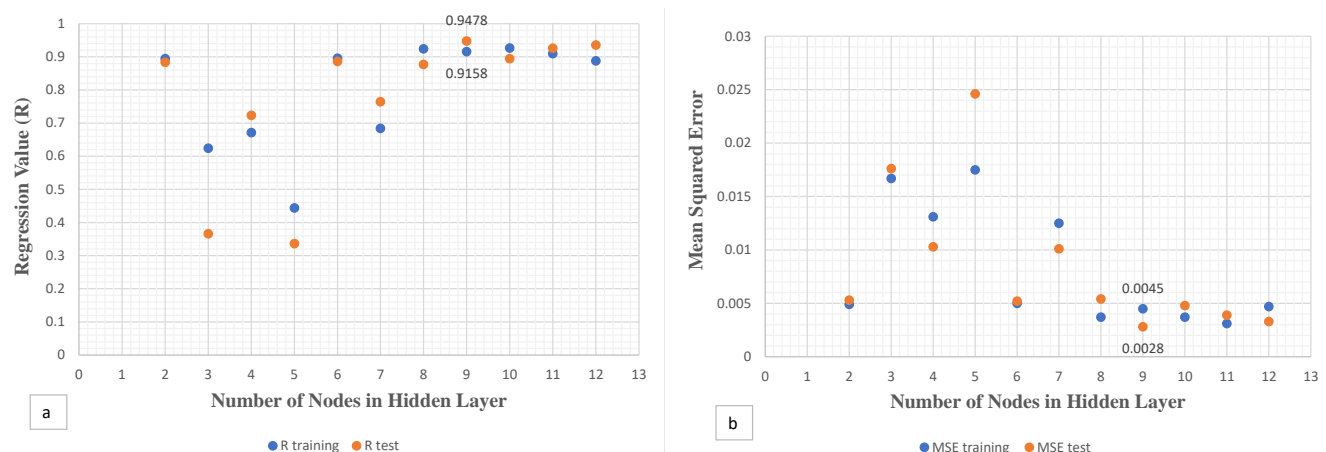

Fig. 8. Performance of ANN model DM-6: (a) R values; (b) MSE 

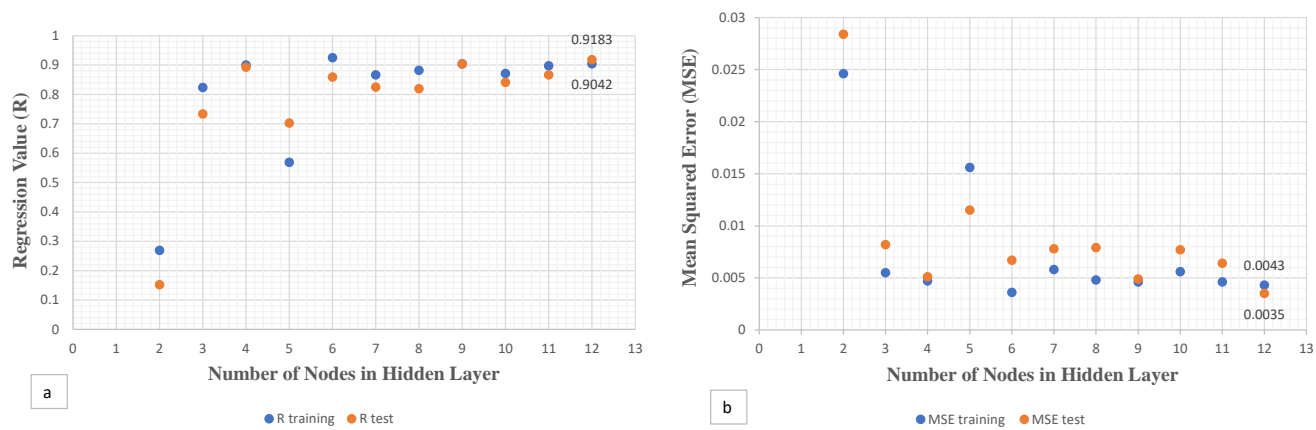

Fig. 9. Performance of ANN model DM-7: (a) R values; (b) MSE

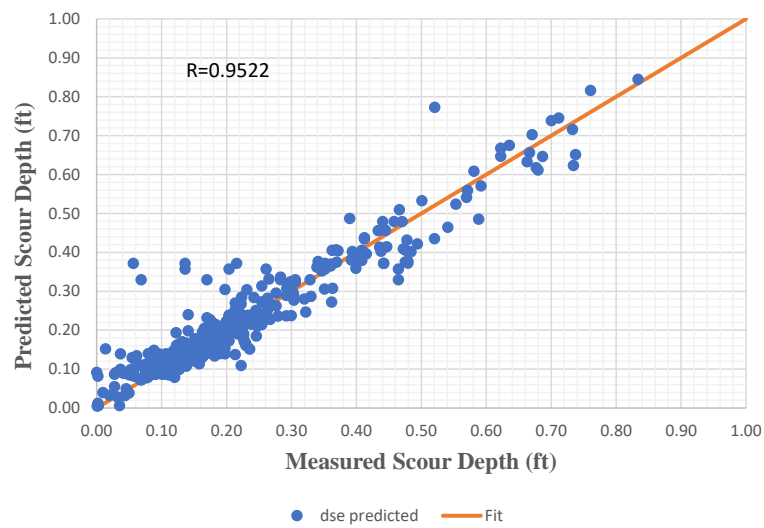

Fig. 10. Predicted equilibrium local scour depth obtained from ANN model DM-1

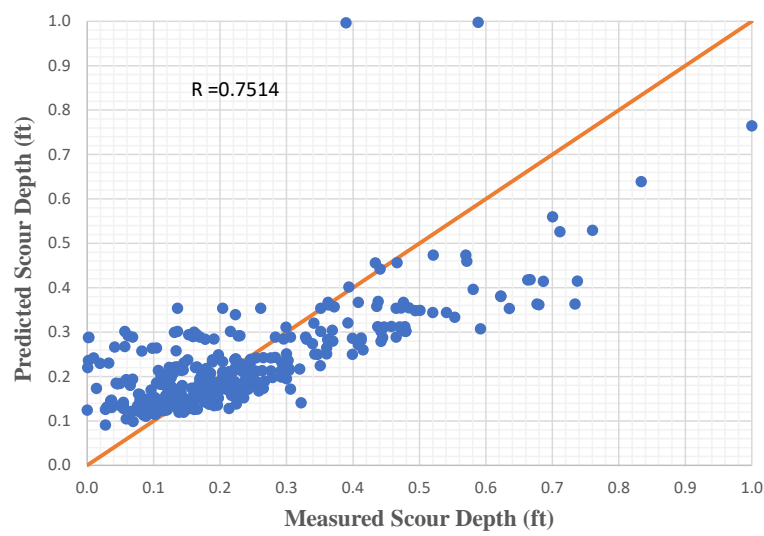

Fig. 11. Predicted equilibrium local scour depth obtained from linear regression model 


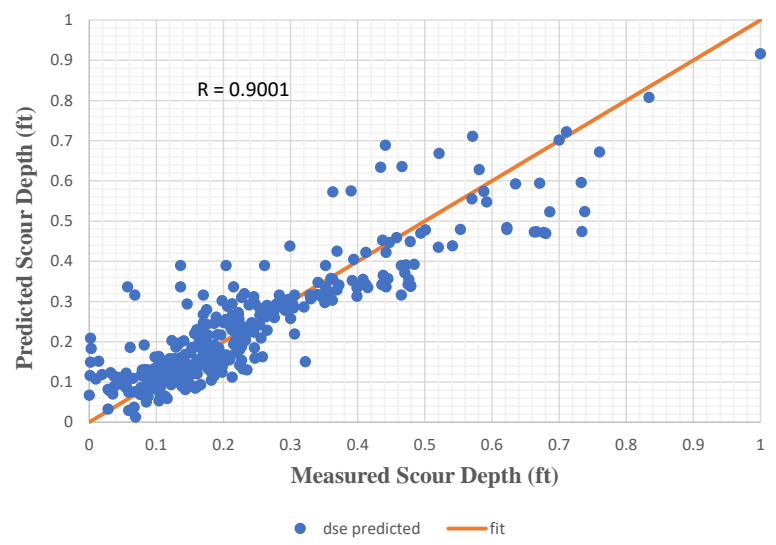

Fig. 12. Predicted equilibrium local scour depth obtained from nonlinear regression model

additional 8 ANN models were established, and each model contained one missed input parameter. Table 6 and Table 7 show the importance of each input parameter in the modeling. It is clear from the results that the pier width $(b)$, as shown in Table 6 , has the most impact on prediction accuracy more than other input parameters. In contrast, the removal of each non-dimensional parameter shows the same effect on the performance of the ANN NDM-1 model.

Table 6. Sensitivity analysis of dimensional parameters

\begin{tabular}{|c|c|c|c|c|c|c|}
\hline Model & R training & MSE training & R test & MSE test & Nodes & $\begin{array}{c}\text { Removed } \\
\text { Parameter }\end{array}$ \\
\hline DM & 0.9585 & 0.0025 & 0.9290 & 0.0032 & 11 & \\
\hline DM1-a & 0.9225 & 0.0028 & 0.9177 & 0.0044 & 11 & $V c$ \\
\hline DM1-b & 0.939 & 0.0027 & 0.9078 & 0.005 & 11 & $V$ \\
\hline DM1-c & 0.5619 & 0.017 & 0.415 & 0.0212 & 11 & $b$ \\
\hline DM1-d & 0.9453 & 0.0026 & 0.9284 & 0.0034 & 11 & $y$ \\
\hline DM1-e & 0.9411 & 0.0025 & 0.9267 & 0.004 & 11 & $d$ \\
\hline
\end{tabular}

Table 7. Sensitivity analysis of non-dimensional parameters

\begin{tabular}{|c|c|c|c|c|c|c|}
\hline Model & R training & MSE training & R test & MSE test & Nodes & $\begin{array}{c}\text { Removed } \\
\text { Parameter }\end{array}$ \\
\hline NDM & 0.7023 & 0.009 & 0.7128 & 0.0088 & 11 & \\
\hline NDM-1a & 0.4994 & 0.015 & 0.4549 & 0.011 & 11 & $\frac{V}{V_{c}}, \frac{y}{b}$, \\
\hline NDM-1b & 0.5286 & 0.014 & 0.3519 & 0.02 & 11 & $\frac{V}{V_{v}}, \frac{d}{b}$, \\
\hline NDM-1c & 0.5578 & 0.136 & 0.4858 & 0.018 & 11 & $\frac{V}{V_{b}}, \frac{b}{b}$, \\
\hline
\end{tabular}




\section{Conclusions}

Artificial neural network models demonstrated a reliable result in predicting equilibrium local scour depth around bridge piers. ANN model DM-1 trained with Levenberg-Marquardt backpropagation (trainlm) algorithm and 11 neurons in the single hidden layer has provided a precise estimation of local scour depth compared to ANN models in this research. Also, the trial-and-error process was used in determining the appropriate number of nodes in the hidden layers. ANN model DM-1 demonstrated better performance than linear and nonlinear regression models. ANN models DM-1, DM-2, and DM-3 provided good performance with 11 nodes in the hidden layer. ANN model DM-4 provided considerable results with 6 and 11 nodes in the hidden layer, while ANN models DM-5 and DM-6 showed promising results with 6 and 9 nodes in the hidden layer, respectively. ANN model DM-7 presented good outcomes with 12 nodes in the hidden layer. It is clear from the results that the small number of nodes in the single hidden layer provides good performance. The sensitivity analysis showed that the availability of the pier width or pier diameter is significant to predicting the equilibrium local scour depth at bridge piers and is more critical than other parameters such as flow depth, flow velocity, and sediment particle size.

\section{References}

Amini A., Hamidi S., Shirzadi A., Behmanesh J., Akib S. (2020) Efficiency of Artificial Neural Networks in Determining Scour Depth at Composite Bridge Piers, International Journal of River Basin Management, 19 (3), 327-333, https://doi.org/10.1080/15715124.2020.1742138.

Azmathullah H. M., Deo M. C., Deolalikar P. B. (2005) Neural networks for estimation of scour downstream of a ski-jump bucket, Journal of Hydraulic Engineering, 131 (10), 898-908, https://doi.org/10.1061/(ASCE)0733-9429(2005)131:10(898).

Bateni S. M., Borghei S. M., Jeng D. S. (2007) Neural network and neuro-fuzzy assessments for scour depth around bridge piers, Engineering Applications of Artificial Intelligence, 20 (3), 401-414, https://doi.org/10.1016/j.engappai.2006.06.012.

Benedict S., Caldwell A. (2014) A pier-scour database-2,427 field and laboratory measurements of pier scour, doi:10.3133/ds845.

Breuser H. N. C., Nicollet G., Shen H. W. (1977) Local scour around cylindrical piers, Journal of Hydraulic Research, 15 (3), 211-252.

Chabert J., Engeldinger P. (1956) Etude des affouillements autour des piles de ponts, Chatou, France: Laboratoire National d'Hydraulique.

Cheremisinoff P. N., Cheremisinoff N. P., Cheng Su Ling (1987) Civil Engineering Practice, Technomic, Lancaster, Pa.

Chee R. K. W. (1982) Live-bed scour at bridge piers, Publication of Auckland University, New Zealand, (290), http://worldcat.org/issn/01110136.

Chiew Y. M. (1984) Local Scour at Bridge Piers, Report No. 355, School of Engg., The Univ. of Auckland, New Zealand.

Choi S. U., Cheong S. (2006) Prediction of local scour around bridge piers using artificial neural networks 1, JAWRA Journal of the American Water Resources Association, 42 (2), 487-494, https://doi.org/10.1111/j.1752-1688.2006.tb03852.x. 
Choi S. U., Choi B., Lee S. (2017) Prediction of local scour around bridge piers using the ANFIS method, Neural Computing and Applications, 28 (2), 335-40-344, https://doi.org/10.1007/s00521-015-2062-1.

Dey S., Bose S. K., Sastry G. L. (1995) Clear water scour at circular piers: a model, Journal of Hydraulic Engineering, 121 (12), 869-876, https://doi.org/10.1061/(ASCE)0733-9429(1995)121:12(869).

Dogan E., Ates A., Yilmaz E. C., Eren B. (2008) Application of artificial neural networks to estimate wastewater treatment plant inlet biochemical oxygen demand, Environmental progress, 27 (4), 439-446, https://doi.org/10.1002/ep.10295.

Dolling O. R., Varas E. A. (2002) Artificial neural networks for streamflow prediction, J. Hydraul. Res., 40 (50), 547-554, https://doi.org/10.1080/00221680209499899.

Ettema R. (1976) Influence of bed gradation on local scour: New Zealand, University of Auckland, School of Engineering (No. 124), Report.

Ettema R. (1980) Scour at bridge piers, Report No. 215, School of Engineering, University of Auckland, Auckland, New Zealand.

Ettema R., Kirkil G., Muste M. (2006) Similitude of large-scale turbulence in experiments on local scour at cylinders, Journal of Hydraulic Engineering, 132 (1), 33-40, https://doi.org/10.1061/(ASCE)0733-9429(2006)132:1(33).

Fletcher D., Goss E. (1993) Forecasting with neural networks: an application using bankruptcy data, Information \& Management, 24 (3), 159-167.

Graf W. H. (1995) Local scour around piers, Annual Report, Laboratoire de Recherches Hydrauliques, Ecole Polytechnique Federale de Lausanne, Lausanne, Switzerland, B.33.1-B.33.8.

Guven A., Azamathulla H. M., Gunal M. (2012) Predicting wave-induced scour around a circular pile, In: Proceedings of the Institution of Civil Engineers-Maritime Engineering, 165 (1), 31-40, Thomas Telford Ltd, https://doi.org/10.1680/maen.2012.165.1.31.

Hagan M., Beale M., Demuth H. (2009) Neural Network ToolboxTM User's Guide, the Math Works, Inc, 6th edition, ISBN: 0-9717321-0-8.

Hagan M. T., Demuth H. B., Beale M. H., Jesus O. (2002) Neural Network Design, ISBN: 978-0-971732-1-7, 2nd Edition.

Hancu S. (1971) Sur le calcul des affouillements locaux dams la zone des piles des ponts, Proceedings of the 14th IAHR Congress, Paris, France, vol. 3, International Association for Hydraulic Research, Delft, The Netherlands, 299-313.

Haykin S. (1999) Neural networks-A comprehensive foundation, 2nd Ed., Prentice-Hall, N.J.

Jain S. C., Fischer, E. E. (1979) Scour around circular bridge piers at high Froude numbers (No. FHWA-RD-79-104 Final Rpt.).

Jeng D. S., Bateni S. M., Lockett E. (2005) Neural network assessment for scour depth around bridge piers, The University of Sydney.

Khassaf S. I., Abdulwhab A. Q. (2016) Modeling of Local Scour Depth Around Bridge Piers Using Artificial Neural Network, Advances in Natural and Applied Sciences, 10 (11), 71-79.

Khwairakpam P., Mazumdar A. (2009) Local scour around hydraulic structures, International Journal of Recent Trends in Engineering, 1 (6), 59.

Laursen E. M., Toch A. (1956) Scour Around Bridge Piers and Abutments, Vol. 4, Ames, IA: Iowa Highway Research Board.

McCulloch W. S., Pitts W. (1943) A logical calculus of the ideas immanent in nervous activity, Univ. Press.

Melville B. W., Coleman S. E. (2000) Bridge scour, Water Resources Publications, LLC, Highlands Ranch, Colo.

Melville B. W., Sutherland A. J. (1988) Design method for local scour at bridge piers, Journal of Hydraulic Engineering, 114 (10), 1210-1226. 
Prasad R., Pandey A., Singh K. P., Singh V. P., Mishra R. K., Singh D. (2012) Retrieval of spinach crop parameters by microwave remote sensing with back propagation artificial neural networks: A comparison of different transfer functions, Advances in space research, 50 (3), 363-370, https://doi.org/10.1016/j.asr.2012.04.010.

Richardson E.., Harrison L. J., Richardson J., Davis S. R. (1991) Evaluating scour at bridges, Federal Highway Administration Hydraulic Engineering Circular No. 18, Publication No. FHWA-IP-90-017, 105 p.

Sarshari E., Mullhaupt P. (2015) Application of Artificial Neural Networks in Assessing The Equilibrium Depth of Local Scour Around Bridge Piers, International Conference on Offshore Mechanics and Arctic Engineering, Vol. 56550, p. V007T06A061, American Society of Mechanical Engineers.

Shen H. W., Schneider V. R., Karaki S. S. (1969) Local scour around bridge piers, Journal of the Hydraulics Division, 95 (HY6), 1919-1940.

Shen H. W.(1971) Scour near piers, in: River mechanics, Vol. II. Chapter 23. Ft. Collins, Colo.

Sheppard D. M., Demir H., Melville B. (2011) Scour at wide piers and long skewed piers, Washington, D.C., Transportation Research Board of the National Academies, NCHRP Report 682, 65 p. 